\title{
Global Research Performance on the Design and Applications of Type-2 Fuzzy Logic Systems: A Bibliometric Analysis
}

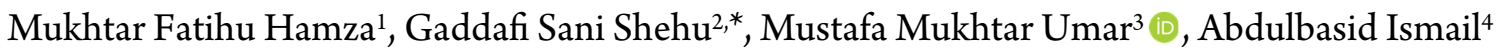 \\ ${ }^{1}$ Department of Mechatronics Engineering, Bayero University Kano, Kano Nigeria. \\ ${ }^{2}$ Department of Electrical Engineering, Ahmadu Bello University Zaria, Nigeria. \\ ${ }^{3}$ Language Lab, Bayero University Kano, Kano Nigeria. \\ ${ }^{4}$ Department of Electrical Engineering, Usmanu Danfodiyo University Sokoto, Nigeria.
}

\begin{abstract}
There has been a significant contribution to scientific literature in the design and applications of Type-2 fuzzy logic systems (T2FLS). The T2FLSs found applications in many aspects of our daily lives, such as engineering, pure science, medicine and social sciences. The online web of science was searched to identify the 100 most frequently cited papers published on the design and application of T2FLS from 1980 to 2016. The articles were analyzed based on authorship, source title, country of origin, institution, document type, web of science category, and year of publication. The correlation between the average citation per year (ACY) and the total citation (TC) was analyzed. It was found that there is a strong relationship between the ACY and TC $(r=0.91643, \mathrm{P}<0.01)$, based on the papers consider in this research. The "Type -2 fuzzy sets made simple" authored by Mendel and John (2002), published in IEEE Transactions on Fuzzy Systems received the highest TC as well as the ACY. The future trend in this research domain was also analyzed. The present analysis may serve as a guide for selecting qualitative literature especially to the beginners in the field of T2FLS.
\end{abstract}

Key words: Type - 2 Fuzzy Logic System, Type - 2 Fuzzy Logic Controller, Type -2 Fuzzy Set, Bibliometrics, Citation.

\section{INTRODUCTION}

The available data in most real world problems are quite associated with uncertainties in nature [1]. These uncertaities are due to a deficiency in information that may be incomplete, imprecise, contradictory, unreliable, vague, fragmentary or deficient in some other ways. Uncertainty is an inherent characteristic of an information [2]. The introduction of fuzzy logic system (FLS) theory increased the ability of systems to cope with the uncertain problems $[2,3]$. The primary feature of fuzzy reasoning allows for handling a different kind of uncertainties[3]. These include easy incorporation of expert knowledge into the control law, less model dependent, robust and can easily be used to model grammatical rules [4]. There are two types of FLS namely, type-1 fuzzy logic system (T1FLS) and Type-2 fuzzy logic system (T2FLS) [5]. In T1FLS, the uncertainty is represented by a precise number in a range of $(0,1)$ interpreted as a degree of membership function (MF). Given the fact that it 's hard to know a precise value for uncertainty, working with T1FLS model is more reasonable. However, some researchers argued that in cases where there is a high level of uncertainty, type-1 fuzzy has limited ability to handle it because its membership degree for each input is a crisp number $[6,7]$. The T2FLS, which uses the type-2 fuzzy set (T2FS), was proposed to avoid the limitations of the T1FLS $[6,8,9]$. The main characteristic of T2FLS is that its MFs are fuzzy. Therefore, it has more degree of freedom (DOF) in designing verities of systems with uncertainties [10-12]. The T2FLS is of two types, namely, Interval type- 2 fuzzy logic system (IT2FLS) that uses interval type-2 fuzzy sets (IT2FSs) and General type-2 fuzzy logic system
(GT2FLS) that uses General type-2 fuzzy sets (GT2FS) [13]. It is argued that in the presence of uncertainty, T2FLS is preferred over T1FLS $[14,15]$. Similarly, there are several records of evidence illustrating some significant improvements regarding accuracy of T2FLS over its counterpart, T1FLS [7, 15-18].

T2FLSs have been used in many types of applications such as intelligent control, pattern recognition, time series forecasting, decision making, classification, modeling, and system identification $[19,20]$. This implies that T2FLS has found application in different study domain like Natural Science, Engineering, Medicine, Social Sciences etc [21, 22]. On the other hand, T2FLSs have been hybridized with other soft computing technique such as Bioinspired Optimization Algorithms (BOA), Artificial Neural Networks (ANN), Sliding Mode Control (SMC) $[23,24]$. This is to simplify its designing method and to improve its performance by utilizing the futures of such soft computing methods. All the mentioned applications and design processes are considered in this study.

In bibliometric analysis contest, the citation indices trace the references in a published article. It shows the number of times a particular paper has been referring to in other articles [25]. In the past decades, the ways to assess citation tracing have been increased significantly [26]. The influence or impact of a particular article can be evaluated

$\begin{array}{ll}\text { Received } & \text { : May 24, } 2019 \\ \text { Revised } & \text { : August 17, 2019 } \\ \text { Accepted } & \text { : August 20, 2019 }\end{array}$


based on how recurrent that item is cited in another article. Though, the number of citations do not indicate the quality of the publication. Obviously, a number of citation alone is not enough to provide a comprehensive measure for judging the quality of scientific articles. Especially due to the existence of several ways to enhance the article citation. However, up to date citation continue to be the primary gauge of the significant of a research output [27].

Bibliometric analysis has been used extensively for evaluating scientific preferences of the research articles for the past decades [25]. In this contest, diverse aspects such as authors, annual publication outputs, language, journals, categories, contributing institutes, publishers, keywords and countries have been studied [26].

Despite the significant of the T2FLS, to the best of the author's knowledge, there is no bibliometric analysis carried out in the field of T2FLS. In this research, the trend of most often cited publications in the area of T2FLS design and applications have been investigated. The analysis of the author keyword and citation in the Institute for Scientific Information database were used to describe the trends of publications in this domain of research during 1980-2016. This study attempted to give insight into state-of-the-art publications in the area of T2FLS applications including author keyword, author analyses, distribution of the publication by country, publication trends, top-cited papers high-performing institutions and collaboration effects. The results offer a well understanding of the trends in T2FLS applications and show the direction for future research.

\subsection{Essential Differences between T1FLS and IT2FLC}

Both the T1FLS and the T2FLS consists of fuzzification and inference blocks, but they differ in the output processing block. In the T2FLC, the output processing block consist of type-reducer and defuzzification blocks, while only defuzzification block is present in T1FLS as shown in Figure 1 (a) and (b).

The are many experimental pieces of evidence that illustrate the superior performance of T2FLS over its T1FLSs counterparts, especially at the high level of uncertainties and nonlinearities [19]. However, the T2FLSs have relatively higher computational cost when compared with T1FLSs. The computational cost is due to the type reduction process, particularly when using the iterative Karnik and Mendel (KM) algorithms [28]. Many approaches have been proposed in the literature to reduce this computational cost [28].

There are many essential differences between T1FLS and T2FLS which are described in detailed by $\mathrm{Wu}$ [29]. The summary of some of the differences are as follows: The T2FLS can be thought of as a group of many diverse embedded T1FLS, and T2FLSs are more adaptive than T1FLSs [30]. Therefore, more complex input/output relationships, which cannot be realized by T1FLSs, can be achieved by IT2FLSs [31]. Also, it was shown that the representation of input/output of FLS with T2FSs resulted in a reduced rule base and increased robustness compared with the representation using T1FSs [29]. Moreover, some experimental evidence indicates that T2FLS can produce a smoother control surface, particularly around the steady state region compared to T1FLS [32-34]. In an IT2FLS, different membership grades from the same IT2FS can be used in various rules in an IT2FLS, whereas the same membership grade from the same T1FS is always employed in different rules in conventional T1FLS. This show that there is a novelty in a T2FLSs that does not exist in conventional T1 FLSs, and it indicated that a T2FLS cannot be implemented by a T1FLS using the same rule base and it is more complicated than a T1FLS [29].

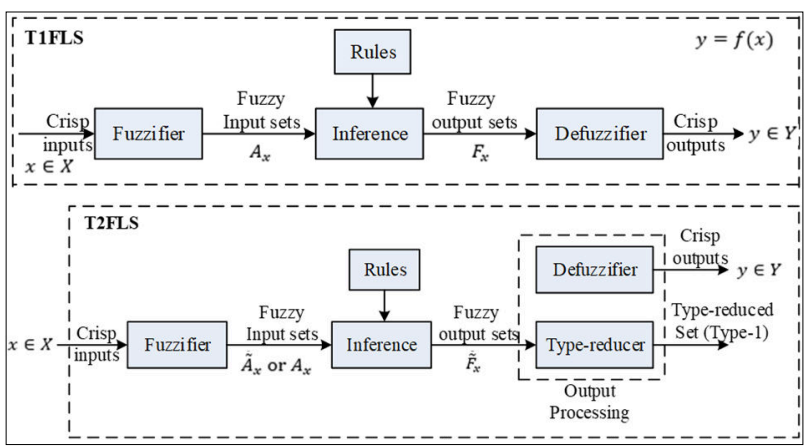

Fig. 1. Fuzzy logic system (a) Type-1, (b) Type-2 (adapted from $[5]$ )

\section{MATERIALS AND METHODS}

The data on the design and applications of type- 2 fuzzy logic systems reported in this study were derived from the Web of Science (Thomson Reuters Web of Science database). This is based on the online version of the Science Citation Index Expanded on August 29th, 2016, for the period of 1980-2016. The key words used for the searching were: (“Type-2 Fuzzy Logic System*"), (“Type-2 Fuzzy Logic Controller*"), ("Interval Type-2 Fuzzy Logic System*”), ("Interval Type-2 Fuzzy Logic Controller*”), ("General Type-2 Fuzzy Logic System*”), ("General Type-2 Fuzzy Logic controller*”), ("Interval Type-2 Fuzzy Set*”), and ("General Type-2 Fuzzy Logic Set"). A total of 1,258 documents were found to meet the criteria of selection.

The Microsoft Excel 2016 was used for analysis of the downloaded data. The manner adopted in selecting the top 100 cited papers is; The most cited articles per year are computed by dividing the total number of citations by the lifespan of the article [35]. To identify the top-cited articles, using the total number of citations per year is prepared scientifically and is more accurate than using the total number of citation only [36]. Abstracts of the top 100 cited papers were retrieved and reviewed to confirm that all the selected papers are within the domain of this study. All the chosen papers are verified to be within the scope of design and application of T2FLS with 92 technical journal article, five review articles, 2 Conference proceeding and one book chapter.

\section{RESULTS AND DISCUSSION}

\subsection{Top 100 most cited papers in design and applications of T2FLS}

Table 1 shows the ranking of the all the top 100 most cited papers in T2FLS design and application. This table indicates the ranking of the article based on their ACY. It also shows the reference, first author name and a total citation (TC) for each paper. The oldest article in the list was 
Table 1 List of 100 Top most cited papers in design and applications of T2FLS

\begin{tabular}{|c|c|c|c|c|c|c|c|c|c|c|c|}
\hline Rank & First Author & $\mathrm{TC}$ & $\mathrm{ACY}$ & Rank & First Author & $\mathrm{TC}$ & $\mathrm{ACY}$ & Rank & First Author & TC & $\mathrm{ACY}$ \\
\hline 1 & Mendel [39] & 820 & 54.67 & 34 & Wang [40] & 57 & 11.4 & 67 & Castillo [41] & 46 & 7.67 \\
\hline 2 & Mendel[42] & 511 & 46.45 & 35 & $\mathrm{Wu}[43]$ & 45 & 11.25 & 68 & $\mathrm{Wu}[44]$ & 46 & 7.67 \\
\hline 3 & Liang $[45]$ & 661 & 38.88 & 36 & Dereli [46] & 65 & 10.83 & 69 & Choi [47] & 60 & 7.5 \\
\hline 4 & Hagras $[48]$ & 407 & 31.31 & 37 & $\mathrm{Wu}[49]$ & 52 & 10.4 & 70 & Zarandi [50] & 60 & 7.5 \\
\hline 5 & Karnik[51] & 559 & 31.06 & 38 & Chen $[52]$ & 41 & 10.25 & 71 & Biglarbegian [53] & 45 & 7.5 \\
\hline 6 & Mendel[54] & 279 & 27.9 & 39 & Liang $[55]$ & 173 & 10.18 & 72 & $\mathrm{Du}[56]$ & 52 & 7.43 \\
\hline 7 & Karnik[57] & 424 & 26.5 & 40 & Abiyev [58] & 71 & 10.14 & 73 & Karnik [37] & 133 & 7.39 \\
\hline 8 & Mendel[59] & 252 & 25.2 & 41 & Mendel $[60]$ & 129 & 9.92 & 74 & $\mathrm{Wu}[61]$ & 44 & 7.33 \\
\hline 9 & Castillo[62] & 117 & 23.4 & 42 & John [63] & 98 & 9.8 & 75 & Hagras [64] & 36 & 7.2 \\
\hline 10 & $\operatorname{Li}[38]$ & 36 & 18 & 43 & Melin [65] & 39 & 9.75 & 76 & Juang [66] & 50 & 7.14 \\
\hline 11 & Hagras [67] & 179 & 17.9 & 44 & Lam [68] & 87 & 9.67 & 77 & Mendel [69] & 71 & 7.1 \\
\hline 12 & Martinez[70] & 142 & 17.75 & 45 & $\mathrm{Wu}[71]$ & 106 & 9.64 & 78 & Zeng [72] & 78 & 7.09 \\
\hline 13 & Wagner[73] & 120 & 17.14 & 46 & Wang [74] & 123 & 9.46 & 79 & Hosseini [75] & 35 & 7 \\
\hline 14 & Karnik[76] & 252 & 15.75 & 47 & Zhai [77] & 56 & 9.33 & 80 & Melin [78] & 41 & 6.83 \\
\hline 15 & Maldonado[79] & 62 & 15.5 & 48 & Khanesar $[80]$ & 46 & 9.2 & 81 & Juang [81] & 54 & 6.75 \\
\hline 16 & $\operatorname{Liu}[82]$ & 134 & 14.89 & 49 & $\mathrm{Wu}[83]$ & 46 & 9.2 & 82 & Mendel [84] & 65 & 6.5 \\
\hline 17 & Biglarbegian [85] & 100 & 14.29 & 50 & $\begin{array}{c}\text { Sepulveda } \\
{[86]}\end{array}$ & 46 & 9.2 & 83 & Liang $[87]$ & 109 & 6.41 \\
\hline 18 & Mendel [88] & 114 & 14.25 & 51 & Aliev [89] & 55 & 9.17 & 84 & Sepulveda $[90]$ & 64 & 6.4 \\
\hline 19 & Castro [91] & 112 & 14 & 52 & $\begin{array}{c}\text { Biglarbegian } \\
{[92]}\end{array}$ & 54 & 9 & 85 & $\mathrm{Oh}[93]$ & 38 & 6.33 \\
\hline 20 & Hwang[94] & 138 & 13.8 & 53 & $\operatorname{Lin}[95]$ & 44 & 8.8 & 86 & Zhai [96] & 38 & 6.33 \\
\hline 21 & $\mathrm{Wu}[97]$ & 206 & 13.73 & 54 & $\operatorname{Lin}[98]$ & 70 & 8.75 & 87 & Hidalgo [99] & 50 & 6.25 \\
\hline 22 & Castillo [100] & 67 & 13.4 & 55 & Castillo [101] & 52 & 8.67 & 88 & Uncu [102] & 60 & 6 \\
\hline 23 & Cornelis [103] & 170 & 13.08 & 56 & $\mathrm{Wu}[104]$ & 60 & 8.57 & 89 & Greenfield [105] & 30 & 6 \\
\hline 24 & Sepulveda [106] & 128 & 12.8 & 57 & Hsiao [107] & 77 & 8.56 & 90 & $\begin{array}{l}\text { Leal-Ramirez } \\
\quad[108]\end{array}$ & 35 & 5.83 \\
\hline 25 & Coupland[109] & 127 & 12.7 & 58 & Yeh [110] & 51 & 8.5 & 91 & $\operatorname{Lin}[111]$ & 46 & 5.75 \\
\hline 26 & Castillo [112] & 38 & 12.67 & 59 & Melin [113] & 59 & 8.43 & 92 & Linda $[114]$ & 34 & 5.67 \\
\hline 27 & Lee[115] & 86 & 12.29 & 60 & $\begin{array}{c}\text { Khosravi } \\
{[116]}\end{array}$ & 42 & 8.4 & 93 & Abiyev [117] & 34 & 5.67 \\
\hline 28 & Hidalgo[118] & 61 & 12.2 & 61 & Jammeh [33] & 67 & 8.38 & 94 & Juang [119] & 45 & 5.62 \\
\hline 29 & $\operatorname{Lam}[120]$ & 36 & 12 & 62 & Linda $[121]$ & 50 & 8.33 & 95 & Mendel [122] & 94 & 5.53 \\
\hline 30 & Greenfield [123] & 95 & 11.88 & 63 & Zhang [124] & 33 & 8.25 & 96 & Coupland [125] & 49 & 5.44 \\
\hline 31 & Juang [126] & 106 & 11.78 & 64 & $\begin{array}{c}\text { Cazarez- } \\
\text { Castro }[127]\end{array}$ & 56 & 8 & 97 & Castillo [128] & 49 & 5.44 \\
\hline 32 & Gaxiola [129] & 35 & 11.67 & 65 & Mendel [130] & 32 & 8 & 98 & Liang $[131]$ & 86 & 5.38 \\
\hline \multirow[t]{2}{*}{33} & $\mathrm{Wu}[132]$ & 116 & 11.6 & 66 & Cao $[133]$ & 55 & 7.86 & 99 & Juang [134] & 48 & 5.33 \\
\hline & & & & & & & & 100 & Sudha [135] & 32 & 5.33 \\
\hline
\end{tabular}

published in the year 1999 by Karnik and Mendel [37] it was ranked 73 and was cited by 133 with 7.39 ACY. The latest paper in the list was published in the year 2015 by Li et al.
[38] ranking 10 and cited by 36 with 18 average citations per year. 
3.2 Comparisons between total citations and averagenumber of citations per year

The descriptive statistics and the scatter diagram for the ACY and TC are presented in Table 2 and Figure 2 respectively. The Pearson correlation coefficient ( $r$ ) was employed to investigate the relationship between TC and the ACY in this domain of research. This is because the TC and ACY in the list of top 100 most cited papers in design and application of T2FLS are normally distributed. The results indicated a high and significant positive relation $(\mathrm{r}=$ $0.91643, \mathrm{P}<0.01$ ) between the TC and ACY in the list of top 100 most cited papers in design and application of T2FLS.

Also, the linear regression was used for the perdition of ACY based on the TC. The significant and very high predictability result was obtained $\left(R^{2}=0.8382 F=513.87\right.$ and $\left.\rho<0.01\right)$ for the linear. Thus, the equation for estimating the ACY based on the TC is:

$\mathrm{ACY}=5.48057+0.05784 \times T C$

Table 2 Descriptive statistics of ACY and TC

\begin{tabular}{ccccccc}
\hline & $\mathrm{N}$ & Mean & $\begin{array}{c}\text { Standard } \\
\text { Deviation }\end{array}$ & $\begin{array}{c}\text { Mini- } \\
\text { mum }\end{array}$ & $\begin{array}{c}\text { Medi- } \\
\text { an }\end{array}$ & $\begin{array}{c}\text { Maxi- } \\
\text { mum }\end{array}$ \\
\hline $\begin{array}{c}\text { AC } \\
\text { Y }\end{array}$ & 100 & 11.66 & 8.26 & 5.33 & 9.185 & 54.67 \\
TC & 100 & 106.84 & 130.79 & 30 & 60 & 820 \\
\hline
\end{tabular}

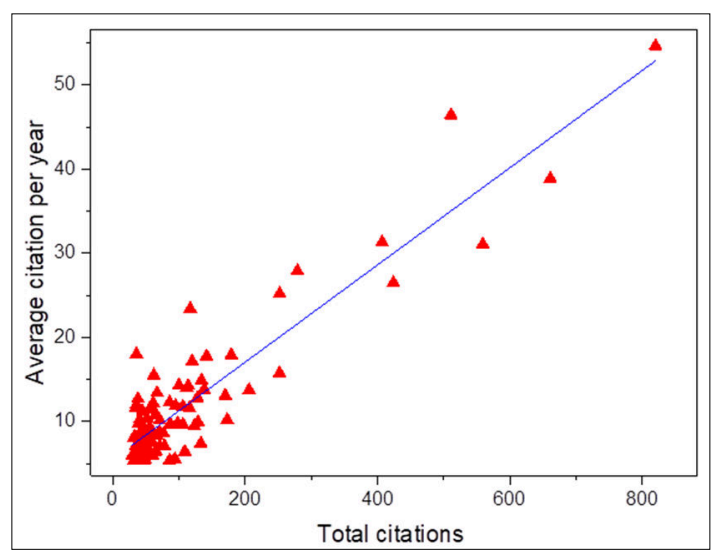

Fig. 2. Scatter diagram for the average citation per year and total citation

\subsection{Most Cited Authors}

The top 5 most cited authors are extracted from the list of all authors who have at least one article in the top 100 most cited papers in T2FLS design and application as a first or co-author. The top 5 authors were evaluated and selected based on the ranking in the top 100 most cited paper list. The presentation of these authors relies on four different indexes. Total number of publications in the top 100 cited list, total number of citations of all author's publications in the top 100 most cited list, summation of the average citation per year of the author's publication in the list, and finally average of Total ACY. Mendel, JM with has a higher number of publications, aggregate citation, and total average citation of 30, 5,581 and 452.82 respectively. However, he obtained the third rank in average citation per year per No of publications. The first rank average citation per year per number of publications was achieved by Karnik, NN with 17.42 from 5 articles. Table 3 shows the summary of the top 5 most cited authors in this domain of research.

Table 3 Summary of the top 5 most cited authors

\begin{tabular}{|c|c|c|c|c|c|}
\hline $\begin{array}{l}\mathrm{R} \\
\mathrm{a} \\
\mathrm{n} \\
\mathrm{k}\end{array}$ & Author & $\begin{array}{c}\text { No of } \\
\text { publica- } \\
\text { tions }\end{array}$ & $\begin{array}{c}\text { Total } \\
\text { TC }\end{array}$ & $\begin{array}{l}\text { Total } \\
\text { ACY }\end{array}$ & $\begin{array}{c}\text { ACY per No } \\
\text { of publica- } \\
\text { tions }\end{array}$ \\
\hline 1 & $\begin{array}{l}\text { Mendel, } \\
\text { JM }\end{array}$ & 30 & 5,581 & 452.82 & 15.10 \\
\hline 2 & $\begin{array}{l}\text { Liang, } \\
\text { QL }\end{array}$ & 6 & 1,588 & 91.91 & 15.31 \\
\hline 3 & $\begin{array}{c}\text { Hagras, } \\
\text { HA }\end{array}$ & 6 & 828 & 85.84 & 14.30 \\
\hline 4 & $\begin{array}{c}\text { Karnik, } \\
\text { NN }\end{array}$ & 5 & 1,477 & 87.11 & 17.42 \\
\hline 5 & $\begin{array}{c}\text { Castillo, } \\
\text { O }\end{array}$ & 21 & 1,299 & 215.26 & 10.25 \\
\hline
\end{tabular}

\subsection{Source Title}

All of the top 100 most cited articles were published in 23 journals; the "IEEE Transactions on Fuzzy Systems" has a higher rank with 33 publications followed by "Information Sciences " with 21 articles. List of the contributing Journal, the number of papers published and the total citations for each journal are shown in Table 4.

Table 4 List of the contributing journals

\begin{tabular}{|c|c|c|c|}
\hline $\begin{array}{l}\mathrm{R} \\
\mathrm{a} \\
\mathrm{n} \\
\mathrm{k}\end{array}$ & Journal Name & $\begin{array}{l}\text { Num- } \\
\text { ber } \\
\text { Publi- } \\
\text { cation }\end{array}$ & $\begin{array}{l}\text { Total } \\
\text { cita- } \\
\text { tion }\end{array}$ \\
\hline 1 & IEEE Transactions on Fuzzy Systems & 33 & 5190 \\
\hline 2 & Information Sciences & 21 & 2195 \\
\hline 3 & Expert Systems with Applications & 6 & 313 \\
\hline 4 & $\begin{array}{l}\text { IEEE Transactions on Systems Man and } \\
\text { Cybernetics Part B-Cybernetics }\end{array}$ & 6 & 443 \\
\hline 5 & Applied Soft Computing & 5 & 320 \\
\hline 6 & IEEE Computational Intelligence Magazine & 3 & 556 \\
\hline 7 & $\begin{array}{l}\text { Engineering Applications of Artificial Intelli- } \\
\text { gence }\end{array}$ & 2 & 152 \\
\hline 7 & $\begin{array}{c}\text { IEEE Transactions on Systems Man and } \\
\text { Cybernetics Part C-Applications and Reviews }\end{array}$ & 2 & 148 \\
\hline 7 & International Journal of General Systems & 2 & 96 \\
\hline 7 & $\begin{array}{l}\text { International Journal of Innovative Compu- } \\
\text { ting Information and Control }\end{array}$ & 2 & 82 \\
\hline 8 & $\begin{array}{c}\text { Analysis and Design of Intelligent Systems } \\
\text { Using Soft Computing Techniques }\end{array}$ & 1 & 64 \\
\hline 8 & Computers in Industry & 1 & 65 \\
\hline 8 & Fuzzy Sets and Systems & 1 & 252 \\
\hline 8 & $\begin{array}{c}\text { IEE Proceedings-Electric Power Applica- } \\
\text { tions }\end{array}$ & 1 & 50 \\
\hline 8 & $\begin{array}{l}\text { IEEE Transactions on Circuits and Systems } \\
\text { Ii-Analog and Digital Signal Processing }\end{array}$ & 1 & 40 \\
\hline 8 & $\begin{array}{c}\text { IEEE Transactions on Intelligent Transpor- } \\
\text { tation Systems }\end{array}$ & 1 & 55 \\
\hline 8 & IEEE Transactions on Power Systems & 1 & 42 \\
\hline 8 & $\begin{array}{l}\text { IEEE Transactions on Systems Man and } \\
\text { Cybernetics Part A-Systems and Humans }\end{array}$ & 1 & 41 \\
\hline 8 & $\begin{array}{l}\text { International Journal of Approximate Reason- } \\
\text { ing }\end{array}$ & 1 & 170 \\
\hline 8 & $\begin{array}{c}\text { Journal of Water Resources Planning and } \\
\text { Management-ASCE }\end{array}$ & 1 & 49 \\
\hline 8 & Knowledge-Based Systems & 1 & 57 \\
\hline 8 & Signal Processing & 1 & 94 \\
\hline 8 & Soft Computing & 1 & 52 \\
\hline
\end{tabular}




\subsection{Institutes with more than one publications}

The author's affiliations in the top 100 most cited papers are used to extract the data for evaluating the performances of the institutions. The number of organizations contributed in publishing the top most cited articles in T2FLS design and application was 68. Among which 47 organizations contribute with only 1 paper, 10 institutions have contributed with 2 articles each, and 11 institutions contributed with three or more papers. As indicated in Table 5. The "Univ So Calif" and the "Tijuana Inst Technol" obtained the higher number of publications of 32 and 18 respectively. Only the institutions with at least two records are presented in Table.

Table 5 List of the contributing institutions

\begin{tabular}{|c|c|}
\hline Institution & No. Publication \\
\hline Univ So Calif & 32 \\
\hline Tijuana Inst Technol & 18 \\
\hline De Montfort Univ & 7 \\
\hline Univ Essex & 7 \\
\hline Natl Chung Hsing Univ & 5 \\
\hline Ge Global Res & 4 \\
\hline Univ Alberta & 3 \\
\hline Ipn & 3 \\
\hline Natl Chiao Tung Univ & 3 \\
\hline Univ Toronto & 3 \\
\hline Univ Waterloo & 3 \\
\hline Tobb Econ Technol Univ & 2 \\
\hline Uabc Univ & 2 \\
\hline Feng Chia Univ & 2 \\
\hline Bogazici Univ & 2 \\
\hline Chien Kuo & 2 \\
\hline Technol Univ & 2 \\
\hline Hanyang Univ & 2 \\
\hline Ind Technol Res Inst & 2 \\
\hline Natl Univ Singapore & 2 \\
\hline Polish Acad Sci & 2 \\
\hline Univ Georgia & 2 \\
\hline
\end{tabular}

\subsection{Countries}

The author's address in the database was used to extract the data for the countries that have contributed in the top most cited article in T2FLS design and application. The total of 15 countries contributed to the list. Among which four countries contributed with only one publication, three countries contributed with two publications while twelve countries contributed with three or more papers. Figure 3 shows that USA has the highs rank with 40 paper flowed by Mexico with 20 articles.

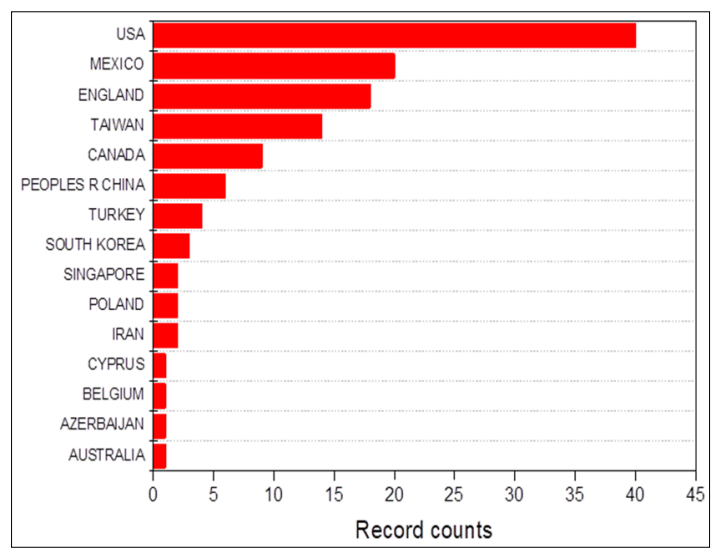

Fig. 3. Distribution of the 100 most cited publications by country

\subsection{Web of Science categories}

The web of science categories for the top 100 most cited papers in T2FLS design and application is shown in Table 6. As indicated from Table 7, the number of publications is higher than 100 , this because some of the journals have more than one category, and the particular web of science category in which the paper is published is not indicated. This mean there is an overlapping. 17 different categories are found in our search, with 5 categories have only one publication; 3 categories with two publications and 9 categories with three or more publications.

Table 6 Web of science categories

\begin{tabular}{cc}
\hline Category & Record \\
\hline Computer Science Artificial Intelligence & 63 \\
Engineering Electrical Electronic & 50 \\
Computer Science Information Systems & 21 \\
Automation Control Systems & 15 \\
Computer Science Interdisciplinary Applica- & 10 \\
tions & 9 \\
Computer Science Cybernetics & 6 \\
Operations Research Management Science & 4 \\
Computer Science Theory Methods & 4 \\
Instruments Instrumentation & 2 \\
Engineering Multidisciplinary & 2 \\
Ergonomics & 2 \\
Engineering Civil & 1 \\
Statistics Probability & 1 \\
Transportation Science Technology & 1 \\
Water Resources & \\
Mathemaineering Industrial & 1 \\
\hline
\end{tabular}




\section{FUTURE TREND}

The pattern of a number of publications per year for the top 100 most cited articles in design and applications of T2FLS is shown in Figure 4. Based on this diagram, it can be seen that the number of publications is higher in the year 2007. Also, the total citation per year for the top 100 most cited articles in design and applications of T2FLS is shown in Figure 5. The citation per year is proved to be increasing. This is likely due to the high number of research in this area. Moreover, the line of best fit was drawn on the scatter diagram of the total citation per year to predict the future of the citation. The result of $\left(R^{2}=0.9126 \rho<0.01\right)$ was found, which means the citation will be increasing per year in future. By increasing the citation, it means the publication will be increasing. This shows that the arear of design and application of T2FLS is a hot are and has the promising future.

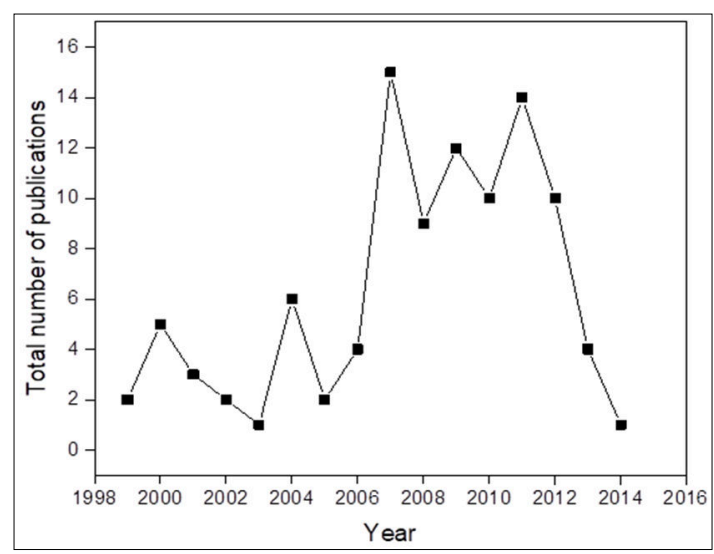

Fig. 4. Trend of number of publication per year

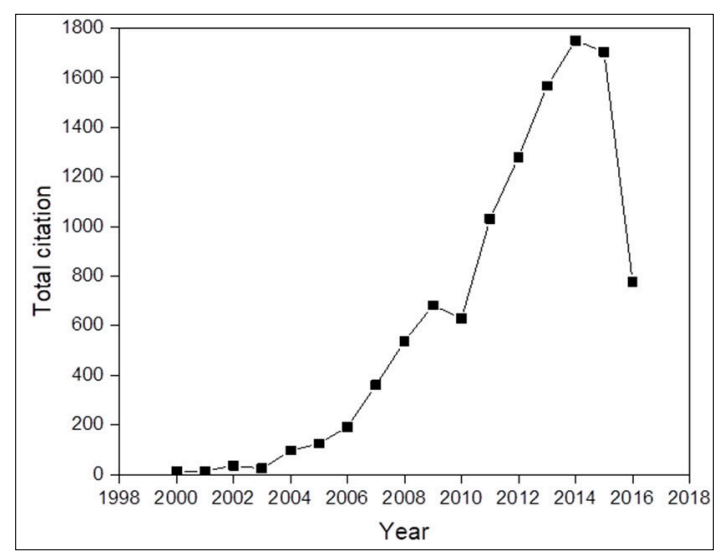

Fig. 5. Total citations per year

\section{LIMITATIONS OF THE STUDY}

It is worth mentioning that the present study cannot be entirely free of methodological deficiency. First, only the papers indexed by the ISI web of science are considered and those that are indexed by database other than ISI web science are omitted. Also, acceptance or rejection of manuscript for publication depend on upon the journal approach. Hence, stringent selection criteria by a journal may affect the quality of that journal. It is therefore not surprising that only 2 journals have contributed $54 \%$ of the top 100 most cited articles. Moreover, citation counts may be affected by other factors including self-citation, nature of the article such as review or open access, prominent authors, as well as the possibility for collaborative citations. Lastly, year of publication has an influence on the number of citations that a particular article can receive. Therefore, papers published recently may not have enough citations to get to the top cited list.

\section{CONCLUSIONS}

This analysis can be considered to be the report on the top most cited papers in T2FLS. The documents extracted from the web of science core collection and arranged according to the total number of citations received over the years. Notably, in this analysis, old papers were favored because longer time allows them to accumulate more citations compared to the recently published articles. Hence, the average number of citations per year was also considered in assessing the quality of this papers. Nevertheless, due to its significant contribution to the understanding of the fundamental concept in T2FLS, the article titled "Type -2 fuzzy sets made simple” by Mendel and John published in 2002 , appeared on top of the pyramid with a total number of 820 citations, and receives an average of 54.67 citations every year.

\section{AUTHOR INFORMATION}

\section{Corresponding Author}

*Email: gsshehu@abu.edu.ng

\section{ORCID}

Mustafa Mukhtar Umar : 0000-0002-5154-904X

\section{REFERENCES}

[1] Mendel JM. Type-2 fuzzy sets and systems: an overview. Computational Intelligence Magazine, IEEE [Internet]. 2007; 2(1):[20-9 pp.]. Available from: http://ieeexplore.ieee.org/ ielx5/10207/4155616/04197699.pdf? $\mathrm{t} \mathrm{p}=$ \&arnumber $=4197699$ \&isnumber $=4155616$.

[2] Zadeh LA. The concept of a linguistic variable and its application to approximate reasoning: Springer; 1974.

[3] Zadeh LA. Fuzzy sets. Information and control [Internet]. 1965; 8(3):[338-53 pp.].

[4] Hamza MF, Yap HJ, Choudhury IA. Genetic Algorithm and Particle Swarm Optimization Based Cascade Interval Type 2 Fuzzy PD Controller for Rotary Inverted Pendulum System. Math Probl Eng. 2015;2015.

[5] Mendel JM, John RI, Feilong L. Interval Type-2 Fuzzy Logic Systems Made Simple. Fuzzy Systems, IEEE Transactions on [Internet]. 2006; 14(6): [808-21 pp.].

[6] Bellman RE, Zadeh LA. Decision-making in a fuzzy environment. Management science [Internet]. 1970; 17(4):[B-141-B-64 pp.].

[7] Kalaivani R, Lakshmi P, Rajeswari K. An improved type-2 fuzzy logic approach based sliding mode controller for vehicle active suspension system. Journal of Vibrational Engineering and Technologies. 2015;3 (4):431-46. 
[8] Castillo O, Melin P, Kacprzyk J, Pedrycz W, editors. Type-2 fuzzy logic: theory and applications. Granular Computing, 2007 GRC 2007 IEEE International Conference on; 2007: IEEE.

[9] Mendel JM, John RIB. Type-2 fuzzy sets made simple. Fuzzy Systems, IEEE Transactions on [Internet]. 2002; 10(2):[117-27 pp.].

[10] Qilian L, Mendel JM. Interval type-2 fuzzy logic systems: theory and design. Fuzzy Systems, IEEE Transactions on [Internet]. 2000; 8(5):[535-50 pp.].

[11] Karnik NN, Mendel JM, Qilian L. Type-2 fuzzy logic systems. Fuzzy Systems, IEEE Transactions on [Internet]. 1999; 7(6):[643-58 pp.].

[12] Karnik NN, Mendel JM, editors. Introduction to type-2 fuzzy logic systems. Fuzzy Systems Proceedings, 1998 IEEE World Congress on Computational Intelligence, The 1998 IEEE International Conference on; 1998 4-9 May 1998.

[13] Mendel JM. General Type-2 Fuzzy Logic Systems Made Simple: A Tutorial. Ieee T Fuzzy Syst [Internet]. 2014 Oct; 22(5):[1162-82 pp.]. Available from: <Go to ISI >://WOS:000344751200010

http://ieeexplore.ieee.org/ ielx7/91/6915776/06656868.pdf? $\mathrm{tp}=$ \&arnumber $=6656868$ \&isnumber $=6915776$.

[14] Ghaemi M, Akbarzadeh-Totonchi M-R. Indirect Adaptive Interval Type-2 Fuzzy PI Sliding Mode Control for a Class of Uncertain Nonlinear Systems. Iran J Fuzzy Syst. 2014;11(5):1-21.

[15] Larguech S, Aloui S, El Hajjaji A, Chaari A, editors. Adaptive Type-2 Fuzzy Sliding Mode Control for MIMO nonlinear systems: Application to a Turbocharged Diesel Engine. Control and Automation (MED), 2015 23th Mediterranean Conference on; 2015: IEEE.

[16] Zirkohi MM, Lin T-C. Interval type-2 fuzzy-neural network indirect adaptive sliding mode control for an active suspension system. Nonlinear Dynam. 2015;79 (1):513-26.

[17] Shabaniniai F, Etedali N, Ghadamyari A. Type-2 fuzzy sliding mode control for deployment of a robotic team. Nonlinear Studies. 2014;21(4):569-78.

[18] Ramesh T, Panda A, Kumar SS. Type-1 and type-2 fuzzy logic and sliding-Mode based speed control of direct torque and flux control induction motor drives-a comparative study. International Journal of Emerging Electric Power Systems. 2013;14(5):385-400.

[19] Hamza MF, Yap HJ, Choudhury IA. Recent advances on the use of meta-heuristic optimization algorithms to optimize the type- 2 fuzzy logic systems in intelligent control. Neural Computing and Applications. 2015: $1-21$.

[20] Hamza MF, Yap HJ, Choudhury IA. Advances on the Use of Meta-Heuristic Algorithms to Optimize Type-2 Fuzzy Logic Systems for Prediction, Classification, Clustering and Pattern Recognition. Journal of Computational and Theoretical Nanoscience. 2016;13 (1):96-109.

[21] Lin YY, Chang JY, Lin CT. A TSK-Type-Based Self-Evolving Compensatory Interval Type-2 Fuzzy
Neural Network (TSCIT2FNN) and Its Applications. Ieee T Ind Electron. 2014;61(1):447-59.

[22] Kundu P, Kar S, Maiti M. Fixed charge transportation problem with type-2 fuzzy variables. Information Sciences. 2014;255:170-86.

[23] Castillo O, Melin P. Optimization of type-2 fuzzy systems based on bio-inspired methods: A concise review. Information Sciences [Internet]. 2012; 205: [1-19 pp.].

[24] Chang YH, Chan WS. Adaptive Dynamic Surface Control for Uncertain Nonlinear Systems With Interval Type-2 Fuzzy Neural Networks. Ieee T Cybernetics. 2014;44(2):293-304.

[25] Sayyad A, Ismail MM, Ale Ebrahim N, editors. Trend of 100 Top-Cited Articles on Agricultural Risk. 2nd Kuala Lumpur International Agriculture, Forestry \& Plantation Conference (KLIAFP 2016), Hotel Putra, Kuala Lumpur, Malaysia; 2016.

[26] De Bakker FG, Groenewegen P, Den Hond F. A bibliometric analysis of 30 years of research and theory on corporate social responsibility and corporate social performance. Business \& Society. 2005;44(3):283-317.

[27] Persson O, Danell R, Schneider JW. How to use Bibexcel for various types of bibliometric analysis. Celebrating scholarly communication studies: A Festschrift for Olle Persson at his 60th Birthday. 2009:9-24.

[28] Wu D. A brief Tutorial on Interval type-2 fuzzy sets and systems. University of Southern California, USA2012. 2010.

[29] $\mathrm{Wu} \mathrm{D}$. On the fundamental differences between interval type- 2 and type-1 fuzzy logic controllers. Ieee T Fuzzy Syst. 2012;20(5):832-48.

[30] Karnik NN, Mendel JM, Liang Q. Type-2 fuzzy logic systems. Ieee T Fuzzy Syst. 1999;7(6):643-58.

[31] Kumbasar T. Robust Stability Analysis and Systematic Design of Single-Input Interval Type-2 Fuzzy Logic Controllers. Ieee T Fuzzy Syst. 2016;24(3):675-94.

[32] Wu D, Tan WW, editors. Interval type-2 fuzzy PI controllers: Why they are more robust. Granular Computing (GrC), 2010 IEEE International Conference on; 2010: IEEE.

[33] Jammeh EA, Fleury M, Wagner C, Hagras H, Ghanbari M. Interval type-2 fuzzy logic congestion control for video streaming across IP networks. Ieee T Fuzzy Syst. 2009;17(5):1123-42.

[34] Martínez-Soto R, Castillo O, Aguilar LT. Type-1 and Type-2 fuzzy logic controller design using a Hybrid PSO-GA optimization method. Information Sciences [Internet]. 2014; 285:[35-49 pp.]. Available from: http://ac.els-cdn.com/S0020025514007026/1-s2.0S0020025514007026-main.pdf? tid=e099e094-d9b9-

11e4-b64800000aac-

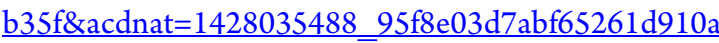
6f165ec3b6.

[35] O'Sullivan KE, Kelly JC, Hurley JP. The 100 most cited publications in cardiac surgery: a bibliometric analysis. Ir J Med Sci. 2015;184(1):91-9. 
[36] Rakhshandehroo M, Yusof MJM, Ebrahim NA, Sharghi A, Arabi R. 100 Most Cited Articles in Urban Green and Open Spaces: A Bibliometric Analysis. Current World Environment. 2015;10(2):445.

[37] Karnik NN, Mendel JM. Applications of type-2 fuzzy logic systems to forecasting of time-series. Information Sciences. 1999;120(1-4):89-111.

[38] Li HY, Sun XJ, Wu LG, Lam HK. State and Output Feedback Control of Interval Type-2 Fuzzy Systems With Mismatched Membership Functions. Ieee $\mathrm{T}$ Fuzzy Syst. 2015;23(6):1943-57.

[39] Mendel JM, John RI. Type-2 fuzzy sets made simple. Ieee T Fuzzy Syst. 2002;10(2):117-27.

[40] Wang WZ, Liu XW, Qin Y. Multi-attribute group decision making models under interval type-2 fuzzy environment. Knowl-Based Syst. 2012;30:121-8.

[41] Castillo O, Melin P, Pedrycz W. Design of interval type -2 fuzzy models through optimal granularity allocation. Applied Soft Computing. 2011;11(8):5590-601.

[42] Mendel JM, John RI, Liu FL. Interval type-2 fuzzy logic systems made simple. Ieee T Fuzzy Syst. 2006;14 (6):808-21.

[43] Wu DR. Approaches for Reducing the Computational Cost of Interval Type-2 Fuzzy Logic Systems: Overview and Comparisons. Ieee $\mathrm{T}$ Fuzzy Syst. 2013;21(1):80-99.

[44] Wu DR, Mendel JM. Linguistic Summarization Using IF-THEN Rules and Interval Type-2 Fuzzy Sets. Ieee T Fuzzy Syst. 2011;19(1):136-51.

[45] Liang QL, Mendel JM. Interval type-2 fuzzy logic systems: Theory and design. Ieee T Fuzzy Syst. 2000;8 (5):535-50.

[46] Dereli T, Baykasoglu A, Altun K, Durmusoglu A, Turksen IB. Industrial applications of type-2 fuzzy sets and systems: A concise review. Computers in Industry. 2011;62(2):125-37.

[47] Choi BI, Rhee FCH. Interval type-2 fuzzy membership function generation methods for pattern recognition. Information Sciences. 2009; 179(13):2102-22.

[48] Hagras HA. A hierarchical type-2 fuzzy logic control architecture for autonomous mobile robots. Ieee $\mathrm{T}$ Fuzzy Syst. 2004;12(4):524-39.

[49] Wu DR, Mendel JM, Coupland S. Enhanced Interval Approach for Encoding Words Into Interval Type-2 Fuzzy Sets and Its Convergence Analysis. Ieee T Fuzzy Syst. 2012;20(3):499-513.

[50] Zarandi MHF, Rezaee B, Turksen IB, Neshat E. A type-2 fuzzy rule-based expert system model for stock price analysis. Expert Systems with Applications. 2009;36(1):139-54.

[51] Karnik NN, Mendel JM, Liang QL. Type-2 fuzzy logic systems. Ieee T Fuzzy Syst. 1999;7(6):643-58.

[52] Chen SM, Wang CY. Fuzzy decision making systems based on interval type-2 fuzzy sets. Information Sciences. 2013;242:1-21.

[53] Biglarbegian M, Melek W, Mendel J. On the robustness of Type-1 and Interval Type-2 fuzzy logic systems in modeling. Information Sciences. 2011;181(7): 1325-47.
[54] Mendel JM. Type-2 fuzzy sets and systems: An overview. Ieee Comput Intell M. 2007;2(1):20-9.

[55] Liang QL, Mendel JM. Equalization of nonlinear time-varying channels using type-2 fuzzy adaptive filters. Ieee T Fuzzy Syst. 2000;8(5):551-63.

[56] Du XY, Ying H. Derivation and Analysis of the Analytical Structures of the Interval Type-2 Fuzzy-PI and PD Controllers. Ieee T Fuzzy Syst. 2010;18 (4):802-14.

[57] Karnik NN, Mendel JM. Centroid of a type-2 fuzzy set. Information Sciences. 2001;132(1-4):195-220.

[58] Abiyev RH, Kaynak O. Type 2 Fuzzy Neural Structure for Identification and Control of Time-Varying Plants. Ieee T Ind Electron. 2010;57(12):4147-59.

[59] Mendel JM. Advances in type-2 fuzzy sets and systems. Information Sciences. 2007; 177(1):84-110.

[60] Mendel JM. Computing derivatives in interval type-2 fuzzy logic systems. Ieee T Fuzzy Syst. 2004;12(1): 84-98.

[61] Wu DR, Mendel JM. On the Continuity of Type-1 and Interval Type-2 Fuzzy Logic Systems. Ieee T Fuzzy Syst. 2011;19(1):179-92.

[62] Castillo O, Melin P. A review on the design and optimization of interval type-2 fuzzy controllers. Applied Soft Computing. 2012;12(4):1267-78.

[63] John RI, Coupland S. Type-2 fuzzy logic: A historical view. Ieee Comput Intell M. 2007;2(1):57-62.

[64] Hagras H, Wagner C. Towards the Wide Spread Use of Type-2 Fuzzy Logic Systems in Real World Applications. Ieee Comput Intell M. 2012;7(3):14-24.

[65] Melin P, Castillo O. A review on the applications of type-2 fuzzy logic in classification and pattern recognition. Expert Systems with Applications. 2013;40(13):5413-23.

[66] Juang CF, Huang RB, Cheng WY. An Interval Type-2 Fuzzy-Neural Network With Support-Vector Regression for Noisy Regression Problems. Ieee $\mathrm{T}$ Fuzzy Syst. 2010;18(4):686-99.

[67] Hagras H. Type-2 FLCs: A new generation of fuzzy controllers. Ieee Comput Intell M. 2007;2(1):30-43.

[68] Lam HK, Seneviratne LD. Stability analysis of interval type-2 fuzzy-model-based control systems. Ieee T Syst Man Cy B. 2008;38(3):617-28.

[69] Mendel JM, Liu FL. Super-exponential convergence of the Karnik-Mendel algorithms for computing the centroid of an interval type-2 fuzzy set. Ieee T Fuzzy Syst. 2007;15(2):309-20.

[70] Martinez R, Castillo O, Aguilar LT. Optimization of interval type-2 fuzzy logic controllers for a perturbed autonomous wheeled mobile robot using genetic algorithms. Information Sciences. 2009;179(13): 2158-74.

[71] Wu DR, Tan WW. Genetic learning and performance evaluation of interval type-2 fuzzy logic controllers. Engineering Applications of Artificial Intelligence. 2006;19(8):829-41.

[72] Zeng J, Liu ZQ. Type-2 fuzzy hidden Markov models and their application to speech recognition. Ieee $\mathrm{T}$ Fuzzy Syst. 2006;14(3):454-67. 
[73] C. Wagner and H. Hagras, "Toward General Type-2 Fuzzy Logic Systems Based on zSlices," Ieee Transactions on Fuzzy Systems, vol. 18, pp. 637-660, Aug 2010.

[74] C. H. Wang, C. S. Cheng, and T. T. Lee, "Dynamical optimal training for interval type-2 fuzzy neural network (T2FNN)," Ieee Transactions on Systems Man and Cybernetics Part B-Cybernetics, vol. 34, pp. 1462-1477, Jun 2004.

[75] R. Hosseini, S. D. Qanadli, S. Barman, M. Mazinani, T. Ellis, and J. Dehmeshki, "An Automatic Approach for Learning and Tuning Gaussian Interval Type-2 Fuzzy Membership Functions Applied to Lung CAD Classification System," Ieee Transactions on Fuzzy Systems, vol. 20, pp. 224-234, Apr 2012.

[76] N. N. Karnik and J. M. Mendel, "Operations on type-2 fuzzy sets," Fuzzy Sets and Systems, vol. 122, pp. 327348, Sep 2001.

[77] D. Y. Zhai and J. M. Mendel, "Uncertainty measures for general Type-2 fuzzy sets," Information Sciences, vol. 181, pp. 503-518, Feb 2011.

[78] P. Melin, O. Mendoza, and O. Castillo, "Face Recognition With an Improved Interval Type-2 Fuzzy Logic Sugeno Integral and Modular Neural Networks," Ieee Transactions on Systems Man and Cybernetics Part a-Systems and Humans, vol. 41, pp. 1001-1012, Sep 2011.

[79] Y. Maldonado, O. Castillo, and P. Melin, "Particle swarm optimization of interval type-2 fuzzy systems for FPGA applications," Applied Soft Computing, vol. 13, pp. 496-508, Jan 2013.

[80] M. A. Khanesar, E. Kayacan, M. Teshnehlab, and O. Kaynak, "Extended Kalman Filter Based Learning Algorithm for Type-2 Fuzzy Logic Systems and Its Experimental Evaluation," Ieee Transactions on Industrial Electronics, vol. 59, pp. 4443-4455, Nov 2012.

[81] C. F. Juang, R. B. Huang, and Y. Y. Lin, "A Recurrent Self-Evolving Interval Type-2 Fuzzy Neural Network for Dynamic System Processing," Ieee Transactions on Fuzzy Systems, vol. 17, pp. 1092-1105, Oct 2009.

[82] F. L. Liu, "An efficient centroid type-reduction strategy for general type-2 fuzzy logic system," Information Sciences, vol. 178, pp. 2224-2236, May 2008.

[83] D. R. Wu, "On the Fundamental Differences Between Interval Type-2 and Type-1 Fuzzy Logic Controllers," Ieee Transactions on Fuzzy Systems, vol. 20, pp. 832848 , Oct 2012.

[84] J. M. Mendel and H. W. Wu, "New results about the centroid of an interval type- 2 fuzzy set, including the centroid of a fuzzy granule," Information Sciences, vol. 177, pp. 360-377, Jan 2007.

[85] M. Biglarbegian, W. W. Melek, and J. M. Mendel, "On the Stability of Interval Type-2 TSK Fuzzy Logic Control Systems," Ieee Transactions on Systems Man and Cybernetics Part B-Cybernetics, vol. 40, pp. 798818, Jun 2010.

[86] R. Sepulveda, O. Montiel, O. Castillo, and P. Melin, "Embedding a high speed interval type-2 fuzzy controller for a real plant into an FPGA," Applied Soft Computing, vol. 12, pp. 988-998, Mar 2012.

[87] Q. L. Liang, N. N. Karnik, and J. M. Mendel, "Connection admission control in ATM networks using survey-based type-2 fuzzy logic systems," Ieee Transactions on Systems Man and Cybernetics Part C -Applications and Reviews, vol. 30, pp. 329-339, Aug 2000.

[88] J. M. Mendel, F. L. Liu, and D. Y. Zhai, "alpha-Plane Representation for Type-2 Fuzzy Sets: Theory and Applications," Ieee Transactions on Fuzzy Systems, vol. 17, pp. 1189-1207, Oct 2009.

[89] R. A. Aliev, W. Pedrycz, B. G. Guirimov, R. R. Aliev, U. Ilhan, M. Babagil, et al., "Type-2 fuzzy neural networks with fuzzy clustering and differential evolution optimization," Information Sciences, vol. 181, pp. 1591-1608, May 2011.

[90] R. Sepulveda, O. Castillo, P. Melin, and O. Montiel, "An efficient computational method to implement type-2 fuzzy logic in control applications," in Analysis and Design of Intelligent Systems Using Soft Computing Techniques. vol. 41, P. Melin, O. Castillo, E. G. Ramirez, J. Kacprzyk, and W. Pedrycz, Eds., ed Berlin: Springer-Verlag Berlin, 2007, pp. 45-52.

[91] J. R. Castro, O. Castillo, P. Melin, and A. RodriguezDiaz, "A hybrid learning algorithm for a class of interval type-2 fuzzy neural networks," Information Sciences, vol. 179, pp. 2175-2193, Jun 2009.

[92] M. Biglarbegian, W. W. Melek, and J. M. Mendel, "Design of Novel Interval Type-2 Fuzzy Controllers for Modular and Reconfigurable Robots: Theory and Experiments," Ieee Transactions on Industrial Electronics, vol. 58, pp. 1371-1384, Apr 2011.

[93] S. K. Oh, H. J. Jang, and W. Pedrycz, "A comparative experimental study of type-1/type- 2 fuzzy cascade controller based on genetic algorithms and particle swarm optimization," Expert Systems with Applications, vol. 38, pp. 11217-11229, Sep 2011.

[94] C. Hwang and F. C. H. Rhee, "Uncertain fuzzy clustering: Interval type-2 fuzzy approach to C-means," Ieee Transactions on Fuzzy Systems, vol. 15, pp. 107-120, Feb 2007.

[95] T. C. Lin, S. W. Chang, and C. H. Hsu, "Robust Adaptive Fuzzy Sliding Mode Control for a Class of Uncertain Discrete-Time Nonlinear Systems," International Journal of Innovative Computing Information and Control, vol. 8, pp. 347-359, Jan 2012.

[96] D. Y. Zhai and J. M. Mendel, "Computing the Centroid of a General Type-2 Fuzzy Set by Means of the Centroid-Flow Algorithm," Ieee Transactions on Fuzzy Systems, vol. 19, pp. 401-422, Jun 2011.

[97] H. W. Wu and J. M. Mendel, "Uncertainty bounds and their use in the design of interval type-2 fuzzy logic systems," Ieee Transactions on Fuzzy Systems, vol. 10, pp. 622-639, Oct 2002.

[98] F. J. Lin and P. H. Chou, "Adaptive Control of Two-Axis Motion Control System Using Interval Type-2 Fuzzy Neural Network," Ieee Transactions on Industrial Electronics, vol. 56, pp. 178-193, Jan 2009. 
[99] D. Hidalgo, O. Castillo, and P. Melin, "Type-1 and type-2 fuzzy inference systems as integration methods in modular neural networks for multimodal biometry and its optimization with genetic algorithms," Information Sciences, vol. 179, pp. 2123-2145, Jun 2009.

[100] O. Castillo and P. Melin, "Optimization of type-2 fuzzy systems based on bio-inspired methods: A concise review," Information Sciences, vol. 205, pp. 119, Nov 2012.

[101] O. Castillo, P. Melin, A. Alanis, O. Montiel, and R. Sepulveda, "Optimization of interval type-2 fuzzy logic controllers using evolutionary algorithms," Soft Computing, vol. 15, pp. 1145-1160, Jun 2011.

[102] O. Uncu and I. B. Turksen, "Discrete interval type 2 fuzzy system models using uncertainty in learning parameters," Ieee Transactions on Fuzzy Systems, vol. 15, pp. 90-106, Feb 2007.

[103] C. Cornelis, G. Deschrijver, and E. E. Kerre, "Implication in intuitionistic fuzzy and interval-valued fuzzy set theory: construction, classification, application," International Journal of Approximate Reasoning, vol. 35, pp. 55-95, Jan 2004.

[104] S. S. Gilan, M. H. Sebt, and V. Shahhosseini, "Computing with words for hierarchical competency based selection of personnel in construction companies," Applied Soft Computing, vol. 12, pp. 860 -871, Feb 2012.

[105] S. Greenfield, F. Chiclana, R. John, and S. Coupland, "The sampling method of defuzzification for type-2 fuzzy sets: Experimental evaluation," Information Sciences, vol. 189, pp. 77-92, Apr 2012.

[106] R. Sepulveda, O. Castillo, P. Melin, A. Rodriguez-Diaz, and O. Montiel, "Experimental study of intelligent controllers under uncertainty using type -1 and type-2 fuzzy logic," Information Sciences, vol. 177, pp. 2023-2048, May 2007.

[107] M. Y. Hsiao, T. H. S. Li, J. Z. Lee, C. H. Chao, and S. H. Tsai, "Design of interval type-2 fuzzy sliding-mode controller," Information Sciences, vol. 178, pp. 16961716, Mar 2008.

[108] C. Leal-Ramirez, O. Castillo, P. Melin, and A. Rodriguez-Diaz, "Simulation of the bird age-structured population growth based on an interval type-2 fuzzy cellular structure," Information Sciences, vol. 181, pp. 519-535, Feb 2011.

[109] S. Coupland and R. I. John, "Geometric type-1 and type-2 fuzzy logic systems," Ieee Transactions on Fuzzy Systems, vol. 15, pp. 3-15, Feb 2007.

[110] C. Y. Yeh, W. H. R. Jeng, and S. J. Lee, "An Enhanced Type-Reduction Algorithm for Type-2 Fuzzy Sets," Ieee Transactions on Fuzzy Systems, vol. 19, pp. 227240, Apr 2011.

[111] T. C. Lin, H. L. Liu, and M. J. Kuo, "Direct adaptive interval type-2 fuzzy control of multivariable nonlinear systems," Engineering Applications of Artificial Intelligence, vol. 22, pp. 420-430, Apr 2009.

[112] O. Castillo and P. Melin, "A review on interval type-2 fuzzy logic applications in intelligent control,"
Information Sciences, vol. 279, pp. 615-631, Sep 2014.

[113] P. Melin, O. Mendoza, and O. Castillo, "An improved method for edge detection based on interval type-2 fuzzy logic," Expert Systems with Applications, vol. 37, pp. 8527-8535, Dec 2010.

[114] O. Linda and M. Manic, "Interval Type-2 fuzzy voter design for fault tolerant systems," Information Sciences, vol. 181, pp. 2933-2950, Jul 2011.

[115] C. S. Lee, M. H. Wang, and H. Hagras, "A Type-2 Fuzzy Ontology and Its Application to Personal Diabetic-Diet Recommendation," Ieee Transactions on Fuzzy Systems, vol. 18, pp. 374-395, Apr 2010.

[116] A. Khosravi, S. Nahavandi, D. Creighton, and D. Srinivasan, "Interval Type-2 Fuzzy Logic Systems for Load Forecasting: A Comparative Study," Ieee Transactions on Power Systems, vol. 27, pp. 12741282, Aug 2012.

[117] R. H. Abiyev, O. Kaynak, T. Alshanableh, and F. Mamedov, "A type-2 neuro-fuzzy system based on clustering and gradient techniques applied to system identification and channel equalization," Applied Soft Computing, vol. 11, pp. 1396-1406, Jan 2011.

[118] D. Hidalgo, P. Melin, and O. Castillo, "An optimization method for designing type-2 fuzzy inference systems based on the footprint of uncertainty using genetic algorithms," Expert Systems with Applications, vol. 39, pp. 4590-4598, Mar 2012.

[119] C. F. Juang and C. H. Hsu, "Reinforcement Interval Type-2 Fuzzy Controller Design by Online Rule Generation and Q-Value-Aided Ant Colony Optimization," Ieee Transactions on Systems Man and Cybernetics Part B-Cybernetics, vol. 39, pp. 1528 -1542, Dec 2009.

[120] H. K. Lam, H. Y. Li, C. Deters, E. L. Secco, H. A. Wurdemann, and K. Althoefer, "Control Design for Interval Type-2 Fuzzy Systems Under Imperfect Premise Matching," Ieee Transactions on Industrial Electronics, vol. 61, pp. 956-968, Feb 2014.

[121] O. Linda and M. Manic, "Uncertainty-Robust Design of Interval Type-2 Fuzzy Logic Controller for Delta Parallel Robot," Ieee Transactions on Industrial Informatics, vol. 7, pp. 661-670, Nov 2011.

[122] J. M. Mendel, "Uncertainty, fuzzy logic, and signal processing," Signal Processing, vol. 80, pp. 913-933, Jun 2000.

[123] S. Greenfield, F. Chiclana, S. Coupland, and R. John, "The collapsing method of defuzzification for discretised interval type-2 fuzzy sets," Information Sciences, vol. 179, pp. 2055-2069, Jun 2009.

[124] Z. M. Zhang and S. H. Zhang, "A novel approach to multi attribute group decision making based on trapezoidal interval type-2 fuzzy soft sets," Applied Mathematical Modelling, vol. 37, pp. 4948-4971, Apr 2013.

[125] S. Coupland and R. I. John, "A Fast Geometric Method for Defuzzification of Type-2 Fuzzy Sets," Ieee Transactions on Fuzzy Systems, vol. 16, pp. 929-941, Aug 2008. 
[126] C. F. Juang and Y. W. Tsao, "A Self-Evolving Interval Type-2 Fuzzy Neural Network With Online Structure and Parameter Learning," Ieee Transactions on Fuzzy Systems, vol. 16, pp. 1411-1424, Dec 2008.

[127] N. R. Cazarez-Castro, L. T. Aguilar, and O. Castillo, "Fuzzy logic control with genetic membership function parameters optimization for the output regulation of a servomechanism with nonlinear backlash," Expert Systems with Applications, vol. 37, pp. 4368-4378, Jun 2010.

[128] O. Castillo, L. Aguilar, N. Cazarez, and S. Cardenas, "Systematic design of a stable type-2 fuzzy logic controller," Applied Soft Computing, vol. 8, pp. 12741279, Jun 2008.

[129] F. Gaxiola, P. Melin, F. Valdez, and O. Castillo, "Interval type-2 fuzzy weight adjustment for backpropagation neural networks with application in time series prediction," Information Sciences, vol. 260, pp. 1-14, Mar 2014.

[130] J. M. Mendel and X. W. Liu, "Simplified Interval Type -2 Fuzzy Logic Systems," Ieee Transactions on Fuzzy Systems, vol. 21, pp. 1056-1069, Dec 2013.

[131] Q. L. Liang and J. M. Mendel, "MPEG VBR video traffic modeling and classification using fuzzy technique," Ieee Transactions on Fuzzy Systems, vol. 9, pp. 183-193, Feb 2001.

[132] D. R. Wu and J. M. Mendel, "Uncertainty measures for interval type-2 fuzzy sets," Information Sciences, vol. 177, pp. 5378-5393, Dec 2007.

[133] J. T. Cao, P. Li, and H. H. Liu, "An Interval Fuzzy Controller for Vehicle Active Suspension Systems," Ieee Transactions on Intelligent Transportation Systems, vol. 11, pp. 885-895, Dec 2010.

[134] C. F. Juang and Y. W. Tsao, "A Type-2 Self-Organizing Neural Fuzzy System and Its FPGA Implementation," Ieee Transactions on Systems Man and Cybernetics Part B-Cybernetics, vol. 38, pp. 1537 -1548, Dec 2008.

[135] K. R. Sudha and R. V. Santhi, "Robust decentralized load frequency control of interconnected power system with Generation Rate Constraint using Type-2 fuzzy approach," International Journal of Electrical Power \& Energy Systems, vol. 33, pp. 699707, Mar 2011.

This article is licensed under a Creative Commons Attriution 4.0 International License. 